\title{
初中数学教学中如何培养学生的反思能力探究
}

\author{
李华 \\ 山东省菏泽市牡丹区实验中学 \\ DOI:10.32629/jief.v2i7.2001
}

[摘 要] 在初中时期是学生累积大量数学知识的关键阶段, 在这一阶段内, 学生需要掌握一定的自我反思能力, 这样才会对数学知识有一个 全新的理解, 才能牢牢掌握住抽象难懂的数学知识, 而教师则需要在教学之中不断培养学生的自我反思能力, 积极地引导学生进行反思, 从 而提高数学课堂效率。

[关键词] 初中数学; 反思能力; 培养

中图分类号: G633.6 文献标识码: A

初中数学一直是初中教育中的难点与重点, 这个学科逻辑性强, 比 较抽象, 不容易学习。所以, 在教师进行数学授课时要注意培养学生的 反思能力, 这样才会不断优化学生的数学思维, 提高学生的学习能力。 所以, 学校需要打破传统, 应用新型的教学方法来培养学生的反思能力, 提高他们的综合素质。

\section{1 初中学生的反思能力对于学好数学至关重要}

在数学学习中反思能力起着很重要的引导性作用, 有着很多中学的 数学教师不停地强调培养学生的思维能力, 可是初中的数学体系跟小学 的数学体系有着很大的不同之处, 初中的数学知识要比小学的要难上许 多, 所以他们往往很难一次性就把所学的数学知识全部掌握, 所以他们 比小学生更需要进行反思。在重新回顾所学知识的过程中, 学生可以有 效地巩固知识并强化他们的解题能力, 从而课堂学习吸收效率才会慢慢 提高。反思是一种对知识的深入理解, 是一种良好的学习习惯, 是初中 学生学习所必不可少的习惯。反思可以帮助学生完善自己的思想架构, 它是一个对知识再检查的过程, 有助于学生更好地探索表层知识下更抽 象更难懂的数学思想; 反思可以完善学生的思维能力, 是一个让学生全 面思考、开阔思路的有效途径。

\section{2 初中数学学生培养反思能力的方法措施}

2.1 培养学生的记笔记做规划习惯

在课堂上, 学生需要集中自己的注意力, 注意每一个细微之处, 把 课上课下的各种疑难点和关键点记录下来, 在自己实在解决不了的情况 下就去询问教师或者其他的同学。教师要积极培养学生记笔记的习惯, 有长期的, 有短期的, 而且要制定出一套适合自己发展的学习计划。而 学生要时常记得去翻看自己制订的学习计划有没有还未完成的地方, 检 查自己是否是高效率完成的, 要及时地制定下一学期的任务和规划。此 外, 要让学生去钻研不同类型有不同解题思路的题型, 让他们记下来容 易错的地方, 以此来找寻最快的解题方法, 这对学生的数学学习会有很 大的帮助。

2.2 问题情境可以训练学生的反思能力

提高数学学习成绩的有效方式就是提高对数学学习的兴趣, 数学极 其抽象, 对学生来说很枯燥, 他们很难从中找到自己学习的乐趣, 特别 是对于那些数学基础本身就很差的学生就更是难上加难了。所以, 教师 需要想方设法地去吸引学生的兴趣, 让他们的思绪停留在数学知识上, 这样才可以有效训练他们的反思思维。教师可以去构造一个问题情境, 在具体的问题情境中, 学生会产生极大地兴趣, 思维会更加活跃, 他们 听讲的课堂积极性也会大幅上升, 在这样的一种具体情境下会很容易激 发学生的反思行为, 培养主动解题的意识。同时, 教师要帮助学生提高 审题的能力, 提高挖掘题目中的隐藏内容, 确定正确的解题思路, 在他
们解题之后, 教师积极引导学生反思解题过程, 并找寻其他解题思路, 做好题目的延伸。

2.3 通过习题帮助学生反思

习题每个学生都会做, 但是想要找到自身的不足之处就需要进行更 深层次的思考了, 不能盲目地做题, 要做一些重点的题型和一些自己经 常出错的题型, 这样会进行更深的反思, 才会提高数学学习能力。这就 需要教师整理学生的学习内容, 对学生做一些针对性的训练来帮助学生 进行反思, 这样才会让学生认识到自身存在的不足之处, 才会进行及时 地改正和调整。与此同时, 教师也需要时常查看学生的反思记录, 通过 不断地提醒来让他们认识到反思的重要性, 引导他们积极主动地去反思, 这样才能够让学生取得一个良好的学习成果。

2.4 通过教师评价训练学生的反思能力

学习过程中, 会犯很多很多的错误, 但是只有不断地改进, 不断地 进行练习, 才能学好知识。在整个过程之中, 反思能力的高低会直接影 响学生学习的最终结果, 学生只有学会怎么反思自己学习的过程才会促 进自己综合素质的提升, 才会全面地发展。但是, 对于初中生来说, 他 们的心智尚不完善, 在很多情况下会出现偏激的情况, 这时候就需要教 师适当地引导和点播学生, 用科学有效的评价方式来帮助学生反思, 逐 步认识到自己的不足之处。这里, 科学的评价既有批评也有表扬, 这种 互相掺杂的方式对提高学生的积极性更有作用, 所以教师应该积极地去 评价学生的学习进程, 不断探索合适的评价方法来更有针对性的去评价。

\section{3 小结}

总而言之, 反思能力对于初中生来说是非常重要的能力, 在教学中, 教师应该积极培养学生的反思习惯, 来帮助他们养成反思的好习惯, 从 而提高课堂效率。但是这种培养不是一朝一夕的事, 需要教师持之以恒 的付出才会取得成效。培养学生反思能力时教师需具备的条件是, 教师 首先要做到不断地反思学习, 吃透教学内容, 创新教学方法, 然后再对 学生进行反思教学。教师是学生学习的榜样, 在对学生反思能力的培养 上, 教师首先要给学生做出榜样。最后, 希望本文总结的一些方法可以 有所帮助。

\section{[参考文献]}

[1]陈再明. 有效构建小学数学互动课堂策略 [N]. 贵州民族 报,2020-08-27(B03).

[2] 曾宪才. 试析小学数学的课堂教学 [N]. 科学导 报,2020-08-25(B03).

[3]王伟.浅谈小学数学高效课堂教学策略 [J]. 河南教育(基教 版),2020(09):56. 